\title{
Impact of key design constraints on fault management strategies for distributed electrical propulsion aircraft
}

\author{
Marie-Claire Flynn*, Catherine E. Jones ${ }^{\dagger}$, Puran Rakhra ${ }^{\ddagger}$, Patrick J. Norman ${ }^{\S}$ and Stuart J. Galloway ${ }^{* *}$ \\ University of Strathclyde, Glasgow, UK, G1 $1 X Q$
}

\begin{abstract}
Electrically driven distributed propulsion has been presented as a possible solution to reduce aircraft noise and emissions, despite increasing global levels of air travel. In order to realise electrical propulsion, novel aircraft electrical systems are required. Since the electrical system must maintain security of power supply to the motors during flight, the protection devices employed on an electrical propulsion aircraft will form a crucial part of system design. However, electrical protection for complex aircraft electrical systems poses a number of challenges, particularly with regard to the weight, volume and efficiency constraints specific to aerospace applications. Furthermore, electrical systems will need to operate at higher power levels and incorporate new technologies, many of which are unproven at altitude and in the harsh aircraft environment. Therefore, today's commercially available aerospace protection technologies are likely to require significant development before they can be considered as part of a fault management strategy for a next generation aircraft. By mapping the protection device trade space based on published literature to date, the discrepancy between the current status of protection devices and the target specifications can be identified for a given time frame. This paper will describe a process of electrical network design that is driven by the protection system requirements, incorporates key technology constraints and analyses the protection device trade space to derive feasible fault management strategies.
\end{abstract}

\section{Introduction}

$\mathrm{E}$ lectrically driven propulsion has been presented as a possible solution to improve aircraft performance, reducing noise and emissions, as global levels of air travel continue to increase by $5 \%$ per year ${ }^{1}$. However, much of the benefit of this concept hinges on the security of supply of electrical power to propulsors driven by electrical motors ${ }^{2}$. Since the electrical system is vital in maintaining sufficient levels of thrust, thus ensuring flight safety, robust electrical fault protection and management is required. The electrical protection system for electrical propulsion aircraft must therefore have a broader scope than that of conventional aircraft electrical systems, due to the increased criticality of the electrical system. The protection system must encompass protection devices, the electrical network architecture, failure modes and redundancy. These aspects of the protection system design for a given aircraft electrical system form the Fault Management Strategy (FMS).

Any FMS for a future aircraft will be subject to a number of aero-specific constraints. The FMS must be efficient, of minimal weight and be capable of an appropriately quick response to fault conditions ${ }^{3}$ to be feasibly implemented on an electrical propulsion aircraft. This is challenging as protection technologies which have been developed for other applications will not have had to adhere to these constraints. This indicates that many conventional protection devices may be unsuitable against a particular aircraft constraint or may not have been proven in the challenging aircraft environment. Overcoming these obstacles requires the availability of high power density, high efficiency protection devices which are of a suitable weight and volume for an aerospace application.

\footnotetext{
${ }^{*} \mathrm{PhD}$ Student, Electronic and Electrical Engineering Department, Student Member.

${ }^{\dagger}$ Research Associate, Electronic and Electrical Engineering Department.

$¥$ Research Associate, Electronic and Electrical Engineering Department.

$\S$ Lecturer, Electronic and Electrical Engineering Department.

** Reader, Electronic and Electrical Engineering Department.
} 
A conventional aircraft electrical design methodology would involve selecting a baseline architecture to meet the aircraft requirements. Then by performing trades with various aspects of electrical system performance, this initial architecture would be altered in an iterative process in order to meet the system constraints, and in doing so, converge on an optimal electrical architecture which incorporates all the necessary design considerations.

Whilst in any electrical architecture design process an initial starting configuration is desired, the authors propose an alternative design methodology as an academic exercise. The design of electrical propulsion aircraft is both challenging and subject to technology barriers. For example, protection devices rated for MW electrical systems which are proven in an aircraft environment do not yet exist, and full scale testing of complete protection systems for electrical propulsion aircraft (including measurement, control, load management and network reconfiguration) have yet to be realised. Therefore, as the protection system for future aircraft is currently subject to a large degree of uncertainty, it is beneficial to reduce the power system architectures solution space by eliminating protection mechanisms which have little probability of success. The suggested novel approach aims to derive electrical architectures, for which an adequate FMS can realistically be implemented using the electrical protection technologies likely to be available within a given developmental timeframe.

This process is iterative, and the selection of FMS and thus architecture would recommence to capture variations in aircraft requirements or available technologies. Since the FMS encapsulates many aspects of system design (e.g. redundancy, choice of AC or DC power, number of power flow channels) it is imperative that the protection system is considered at the outset, together with the design of the aircraft configuration. This prevents an electrical architecture from being selected for an aircraft for which there are no suitable protection devices, or where the benefits of the electrical propulsion system are negated by the weight penalty associated with their use.

\section{A. Technology Roadmaps and Developments}

The expected Entry Into Service (EIS) for various sizes and power ratings of electrical propulsion aircraft are staggered across a number of defined timeframes, ranging from the present $(\mathrm{N})$ to around $2040(\mathrm{~N}+4)^{4}$. Aircraft manufacturers must be able to finalise the electrical system design an appropriate period of time prior to the actual EIS for the aircraft. Therefore, electrical protection devices must have reached high TRL, demonstrated the required specifications and passed certification standards at this aircraft definition stage if they are to be suitable for use.

As aircraft electrical systems evolve across a range of power transmission arrangements (AC, DC or a mixed combination) a greater variety of devices will be required to match these advances in system configuration. The addition of large propulsive loads on the system and increased electrification of subsystems, means that future aircraft protection devices will also have to operate at higher power ratings. This is likely to require novel protection devices such as MVDC (Medium Voltage Direct Current) breakers and Superconducting Fault Current Limiters (SCFLs), both of which are unproven in an aircraft application. Therefore, today's commercially available protection devices are likely to require significant development or substitution by a superior technology before the stringent FMS design criteria can be met. Current and near future electrical propulsion aircraft are limited to small scale demonstrators or general aviation aircraft. However, the number of passengers per aircraft and the electrical power ratings are set to increase incrementally, with fully electric large passenger aircraft remaining a long term goal.

\section{Database Criteria}

In order to assess the discrepancy between current state-of-the-art and future optimal protection system capability, it is necessary to establish the landscape regarding protection devices. A knowledge database has been compiled to illustrate the current level of development of a variety of circuit breakers, SFCLs and power electronics converters (which can offer a range of fault management functions) potentially suitable for distributed propulsion aircraft applications. Since the rate of improvement of various technologies is unknown, devices have been considered across a range of TRLs (Technology Readiness Level), from patented technologies to commercial products. This database will be reviewed regularly in order to capture any shift in industry focus or significant improvements in a given protection technology.

\section{B. Technology Readiness Level Selection}

The TRL for each device or project in the database was categorised based on the TRL stages developed by NASA 5 . The exact TRL level (0-9) for some projects is difficult to ascertain based on the published data, so the TRL rating has been simplified into three broad stages as follows:

1) Low TRL - evidence of patents, computational modelling and simulations or conceptual description

2) Medium TRL - evidence of lab based prototype, hardware testing or scaling up of initial testing

3) High TRL - evidence of extensive in-field testing or commercially available 
The TRL listed in the database is based on the latest available publications and is noted alongside the date of publication for completeness.

\section{Cross-discipline Technologies}

The database presented in this paper enables identification of complexities introduced when applying devices ordinarily used within HVDC (High Voltage Direct Current) systems, traction applications, terrestrial grids, naval and marine systems, solar systems and electric vehicles to electrical propulsion aircraft. In reviewing the literature and compiling the database to this point it is clear that there are no off-the-shelf protection devices which are currently suitable for future aircraft. Therefore, in the first instance, devices which have been developed for other applications must be considered. In order to demonstrate this, a number of application areas with particular relevance to aircraft electrical systems are discussed below.

\section{1. $H V D C$}

HVDC electrical systems are advancing DC power technologies such as high voltage DC converters ${ }^{6}$. This may be beneficial where aircraft systems are DC, since the TRL level and availability of devices should increase. This area of the industry has also identified the need for standardisation of technologies and operating points, such as a common DC voltage level ${ }^{7}$. As the standards for novel aircraft electrical systems are still under development and remain largely undefined, this will prove useful as an indicator of the level of standards that future electrical aircraft protection devices will have to comply with.

\section{Terrestrial Grid}

Micro-grids and smart grids are another application area with relevance to future aircraft. The type of protection devices deployed on the national grid are normally large, robust, well established technologies, which dictates that there would need to be a reduction in scale to aircraft systems. However, the pressure on the network to maintain everincreasing levels of supply and manage distributed generation mean that greater flexibility of network management and protection is needed. This has led to the development and installation of novel SFCLs on congested networks ${ }^{8,9}$ in the UK. If SFCLs can be proven in the field as a cost-effective and reliable means of reducing maximum fault current, then there is a possibility that SFCLs might transfer to other applications where fault current limitation may provide significant benefits. The increased level of monitoring and measurement that is being applied to smart grids ${ }^{10}$ is also interesting for electric propulsion aircraft as the critical power train network is likely to include a large number of sensors to ensure power quality and delivery is maintained.

\section{Naval and Marine}

Naval protection devices are of particular interest as there is a similar need for high reliability, high power density and high speed of response, while the fact that naval electrical propulsion systems have reached a higher maturity provides a testing ground for new technologies. Whilst naval systems are subject to weight and volume constraints, these are not as stringent as for aircraft applications, and so it is not clear if and how devices and architecture configurations will scale down. The naval circuit breaker devices and fault current limiters listed in the database are much too sizeable for aircraft at present, and so reduction in weight and volume remains a key developmental goal. Furthermore, electrical standards for the US Navy electric warship program are already under development ${ }^{11}$, and this is seen as a key part of integrating electrical power technologies into future vessels. This provides a good basis for the development of standards for future electrical aircraft systems as these specifications can be used as a reference for standardising aspects of MVDC distribution and novel protection mechanisms.

\section{Solar}

Solar energy systems present an opportunity to advance aircraft protection technology. Since it is highly likely that energy storage (possibly in the form of batteries, super capacitors, or magnetic energy storage) will play a role in either the normal or faulted operation of the power train system, this requires power conversion where the system is $\mathrm{AC}$, or energy storage control where the system is DC. As the size of solar power plants have increased over recent years the power conversion devices which have been developed to support this integration to the wider grid have also achieved higher power ratings and reduced losses. However, similar to the naval systems these devices are still not on a scale that would be feasible for an aircraft. Furthermore, there is a difference in how the energy storage is applied to the network. The energy storage on an aircraft may need to be distributed throughout the network, as opposed to one single converter supporting a large section of storage energy. Therefore, aircraft (again depending on the architecture) may require multiple small, high power converters instead of a single large converter. This highlights that there is a 
possible complexity in applying this technology to aircraft, as it may not be possible to achieve similar levels of power rating in a smaller scale device, whilst maintaining high efficiencies.

\section{Electric Vehicle}

Electric and hybrid electric vehicles are becoming increasingly common across the automotive sector, from Formula $1^{12}$ to leisure buggies to taxis ${ }^{13}$. Whilst the power levels are not comparable to aircraft electrical propulsion, the focus on improving power density implies that protection devices for electric vehicles are likely to become more compact. Automotive electrical power systems also require high level of safety criticality, similar to aircraft electrical power systems. Aircraft protection devices should reflect a similar level of improvement over time. Electric vehicles are also changing the public perception of electric transport and are demonstrating the feasibility of electric systems replacing fossil fuel combustion engines.

\section{Traction Vehicles}

Electric power in traction vehicles is a well-established technology and so offers a useful comparison point for protection technology development. Although the weight of the system is much less of a constraint in traction applications compared to aircraft, there is extensive use of DC power transmission which may inform the use of DC networks on aircraft. Furthermore, electrified railways allow a noise reduction in the vicinity of the track, particularly where rails pass through residential areas. The potential to reduce noise is also a key driver for electrical propulsion aircraft, especially given the aggressive noise reduction targets that have been identified by both NASA and the $\mathrm{EU}^{14}$.

\section{Validity of Database Content}

The database was compiled from recent protection device publications. It will require regular updates to reflect developments in the technology. However, the date of publication may not in fact reflect the actual status of a current project and so there is a degree of uncertainty in interpreting the availability of different devices. An additional challenge is that data on some of the most pertinent and promising protection devices being commercially developed may not be available in the public domain. The purpose of this paper is not to attempt to scope all possible protection devices, but rather to give a snap shot of the current situation as far as possible, and to use that as a basis for a first pass assessment of feasible FMSs. If a particular FMS is then selected from the range of possible FMS outcomes that have been identified, then the next iteration of the literature review would be refocused to reflect this and the database would be updated to include any relevant technologies or devices which may have not have been identified in the first instance.

\section{Protection Device Database}

\section{A. Circuit Breakers}

Circuit breakers perform the key function of isolating a faulted section of the power system from the remainder of the network, often under high current conditions. This functionality is essential in the realisation of safety critical systems. Whilst the developed database contains information on both AC and DC circuit breaking technologies, this paper will focus primarily on the DC breakers as DC transmission and distribution on an aircraft is considered as a possible future electrical configuration which offers a number of benefits, including:

1) Electrical decoupling of the generators and motors, increasing efficiency of the machines

2) Greater flexibility of control of individual propulsor motors where propulsion is distributed across an array of motors

3) Simpler integration of DC energy storage devices such as batteries, with less complex power electronics.

Since any section of MVDC network is likely to require a circuit breaker, MVDC circuit breakers are an important protection technology for future aircraft. A review of state-of-the-art DC circuit breakers was undertaken, with summary data stored in the protection device database. An excerpt of the data gathered is shown in Table 1, ordered by TRL level then by date of publication.

\section{B. Power Electronic Converters}

Power electronics converters enable electrical decoupling of the motors from the generators or energy storage. A decision has not been made as to the conditions for which either AC or DC transmission is preferable, yet it is likely 
that power electronics (AC-DC or AC-AC) will be required at the interface between the electrical machines and the network. However, further studies, which are beyond the scope of this paper, are necessary to fully understand the limits of converterless AC systems. This reinforces the notion that since the electrical architecture will be strongly influenced by the feasible fault management solutions, and the FMS must define the electrical network design. By control of the solid state switches (manipulating firing angle ${ }^{15,16,17}$, pulse width modulation control ${ }^{18}$ ) or current blocking diodes ${ }^{19}$ within some topologies of power converters it is possible to limit fault current or de-energise the downstream network when a fault occurs. If converters are included in an architecture for power conditioning purposes, exploiting this potential dual functionality may provide a weight and efficiency benefit. The type of switches and the chosen semi-conductor material is also an area for consideration, since this impacts on voltage ratings, switching frequency, packaging etc., and is therefore relevant to the final weight and efficiency of the converter. A review of devices which are currently in development across a range of application areas was undertaken to assess the viability of this technology for use in a FMS. A selection of the data obtained in the database is shown in Table 3.

Table 1: Excerpt of data from DC Circuit Breaker database

\begin{tabular}{|c|c|c|c|c|c|}
\hline Developer & Technology Type & Application & $\begin{array}{l}\text { Voltage } \\
\text { Rating }(\mathrm{kV})\end{array}$ & TRL & $\begin{array}{ll}\text { Date } & \text { of } \\
\text { Publication } & \end{array}$ \\
\hline Eaton $\mathrm{AVD}^{60}$ & $\begin{array}{l}\text { Solid State DC } \\
\text { Breaker }\end{array}$ & Naval & 2 & High & 2007 \\
\hline $\begin{array}{l}\text { Helmut Schmidt University, } \\
\text { Airbus Group Innovation }{ }^{44}\end{array}$ & HVDC SSPC & $\begin{array}{l}\text { MEA/ } \\
\text { Future DC } \\
\text { aircraft grids }\end{array}$ & 0.54 & Medium & 2000 \\
\hline $\begin{array}{l}\text { Virginia Polytech. Inst. \& } \\
\text { State Univ }\end{array}$ & $\begin{array}{l}\text { Emitter Turn-off } \\
\text { Thyristor-based DC } \\
\text { Circuit Breaker }\end{array}$ & $\begin{array}{l}\text { High power } \\
\text { systems }\end{array}$ & 2.5 & Medium & 2002 \\
\hline $\begin{array}{l}\text { ABB Schweiz, Ecole } \\
\text { Polytechnique } \\
\text { Fédérale de Lausanne }{ }^{62}\end{array}$ & Hybrid CB IGCTs & Rail & 1.5 & Medium & 2006 \\
\hline $\begin{array}{l}\text { Industrial Education } \\
\text { College, Cairo, Northumbria } \\
\text { University, University of } \\
\text { Durham }^{63}\end{array}$ & $\begin{array}{l}\text { Solid-State Fault- } \\
\text { Current Limiting } \\
\text { and Interrupting } \\
\text { Device }\end{array}$ & $\begin{array}{l}\text { LV } \\
\text { Distribution } \\
\text { networks }\end{array}$ & 0.23 & Medium & 2006 \\
\hline $\mathrm{ABB}^{64}$ & HVDC Breaker & Grid & 320 & Medium & 2012 \\
\hline $\begin{array}{l}\text { Eidgenössischen } \\
\text { Technischen Hochschule } \\
\text { Zürich }^{65}\end{array}$ & Hybrid DC breaker & MVDC & 12 & Medium & 2001 \\
\hline $\begin{array}{l}\text { Diversified Technologies, } \\
\text { Inc. }{ }^{66}\end{array}$ & $\begin{array}{l}\text { MVDC IGBT } \\
\text { Converter }\end{array}$ & Naval & $10-20$ & Low & 2011 \\
\hline Creative Energy Solutions ${ }^{67}$ & $\begin{array}{l}\text { Z source breaker } \\
\text { DC }\end{array}$ & Naval & 6 & Low & 2010 \\
\hline $\begin{array}{l}\text { MIT Sea Grant College } \\
\text { Program } 68\end{array}$ & $\begin{array}{l}\text { Improved } \mathrm{z} \text { source } \\
\text { breaker }\end{array}$ & Naval & 6 & Low & 2011 \\
\hline
\end{tabular}


Table 3: Excerpt from power converter database

\begin{tabular}{|l|l|l|l|l|ll|}
\hline Developer & Technology & $\begin{array}{l}\text { Year of } \\
\text { Publication }\end{array}$ & $\begin{array}{l}\text { TRL } \\
\text { level }\end{array}$ & $\begin{array}{l}\text { Power } \\
\text { Rating }\end{array}$ & Application \\
\hline $\begin{array}{l}\text { Universität der Bundeswehr, } \\
\text { Siemens }\end{array}$ & $\begin{array}{l}\text { AC-AC } \\
\text { converter }\end{array}$ & 2005 & Medium & $5 \mathrm{MW}$ & $\begin{array}{l}\text { AC driven traction } \\
\text { vehicles }\end{array}$ \\
\hline $\begin{array}{l}\text { Pusan National University, } \\
\text { Pusan, Republic of Korea }\end{array}$ & CSI & 2007 & Medium & $1.2 \mathrm{kVA}$ & $\begin{array}{l}\text { Solar PV connection to } \\
\text { grid }\end{array}$ \\
\hline Ruhr-University Bochum & & MMC & 2013 & Medium & $3.9 \mathrm{MW}$ & Shipboard systems \\
\hline $\begin{array}{l}\text { Florida State University, } \\
\text { ABB }^{18}\end{array}$ & MMC AC-DC & 2015 & Medium & $\begin{array}{l}1.25 \\
\text { MVA }\end{array}$ & Shipboard systems \\
\hline University of Aberdeen & & & & \\
\hline $\begin{array}{l}\text { Southeast University, China } \\
\text { and Hong Kong University }\end{array}$ & DC-DC & CSC & 2009 & Low & $5 \mathrm{MW}$ & $\begin{array}{l}\text { DC source to grid } \\
\text { interface }\end{array}$ \\
\hline
\end{tabular}

Table 2: Excerpt from SFCL database

\begin{tabular}{|c|c|c|c|c|c|c|c|}
\hline Developer & Technology & Phases & $\begin{array}{l}\text { Voltage } \\
(\mathrm{kV})\end{array}$ & $\begin{array}{l}\text { TRL } \\
\text { level }\end{array}$ & $\begin{array}{l}\text { Weight } \\
(\mathrm{kg})\end{array}$ & Application & $\begin{array}{l}\text { Year of } \\
\text { Publication }\end{array}$ \\
\hline SuperPower $^{74}$ & Resistive & 1-phase & 8.6 & High & $\approx 3000$ & Grid & 2006 \\
\hline $\mathrm{CAS}^{75}$ & $\begin{array}{l}\text { Rectifier } \\
\text { Type }\end{array}$ & 3-phase & 10.5 & High & Unknown & Grid & 2006 \\
\hline $\begin{array}{l}\text { Innovative } \\
\text { Technomics USA } \\
\text { LLC }^{76}\end{array}$ & $\begin{array}{l}\text { Dynamic } \\
\text { ambient } \\
\text { temperature } \\
\text { magnetic core }\end{array}$ & 3-phase & 12 & High & Unknown & Naval & 2011 \\
\hline Innopower ${ }^{77}$ & $\begin{array}{l}\text { Saturable } \\
\text { Core }\end{array}$ & 3-phase & 35 & High & 27000 & Grid & 2009 \\
\hline Zenergy $^{77}$ & $\begin{array}{l}\text { Saturable } \\
\text { Core }\end{array}$ & 3-phase & 15 & High & 20000 & Grid & 2009 \\
\hline Nexans $^{20}$ & Hybrid & 3-phase & 24 & High & Unknown & Grid & 2012 \\
\hline Nexans $^{20}$ & Resistive & 3-phase & 12 & High & 2500 & Grid & 2012 \\
\hline $\begin{array}{l}\text { DAPAS Korea, } \\
\text { KEPRI/LSIS }{ }^{20}\end{array}$ & Hybrid & 3-phase & 22.9 & High & 907 & Grid & 2012 \\
\hline $\begin{array}{l}\text { Applied } \\
\text { Superconductor } \\
\text { Limited, Northern } \\
\text { Powergrid }^{9}\end{array}$ & $\begin{array}{l}\text { Saturated } \\
\text { Core }\end{array}$ & 3-phase & 33 & High & Unknown & Grid & 2013 \\
\hline Hyundai $^{78}$ & Resistive & 1-phase & 13.2 & Medium & Unknown & Grid & 2008 \\
\hline Siemens/AMSC ${ }^{79}$ & Resistive & 1-phase & 7.5 & Medium & Unknown & Grid & 2008 \\
\hline $\begin{array}{l}\text { Arkansas Power } \\
\text { Electronics } \\
\text { International, } \\
\text { Inc. }^{41}\end{array}$ & Solid state & 1-phase & 4.16 & Medium & Unknown & Naval & 2009 \\
\hline $\begin{array}{l}\text { University of } \\
\text { Wollongong/ } \\
\text { Zenergy }^{80}\end{array}$ & $\begin{array}{l}\text { Saturated } \\
\text { Core }\end{array}$ & 3-phase & $\begin{array}{l}0.4 \text { (line- } \\
\text { line) }\end{array}$ & Medium & Unknown & Grid & 2009 \\
\hline $\begin{array}{l}\text { Toshiba, Fujikura } \\
\text { Ltd }^{81}\end{array}$ & Magnetic coil & 3-phase & 6.6 & Medium & Unknown & Grid & 2009 \\
\hline ERSE Spa $^{20}$ & Resistive & 3-phase & 9 & Medium & 3800 & Grid & 2012 \\
\hline $\begin{array}{l}\text { AMSC, Siemens, } \\
\text { and Nexans }{ }^{20}\end{array}$ & Hybrid & 1-phase & 138 & $\begin{array}{l}\text { Medium/ } \\
\text { High }\end{array}$ & 40000 & Grid & 2012 \\
\hline
\end{tabular}


It is important to note that the applicability of developmental devices to a future aircraft, especially those for use in other industries, has not yet been demonstrated. Technology functions and specifications may alter as devices reach higher TRL and there is no guarantee that any particular capability of a protection system for a non-aircraft application will be feasibly implemented on an electrical propulsion aircraft.

\section{Fault Current Limiters}

When a fault occurs on a compact, low impedance network, a large fault current can be seen in the system. The maximum fault current which the system will experience will depend on the location of the fault, the fault path impedance and the power sources (such as DC link capacitances) which will feed current into the fault. Thus the fault current, if large or sustained, can cause significant damage to components on the network. The use of fault current limiters reduces that maximum fault current rating of devices, since the current is prevented from reaching its peak. This functionality can be performed in a variety of ways, including:

1) Fast acting differential protection which measures the di/dt of the current and manipulates circuit breakers to isolate the fault when the di/dt rating is at fault level (interruption prior to current peak)

2) Control of power electronic switches in converters to switch off at a threshold current value (interruption prior to current peak)

3) Solid state and Superconducting Fault Current Limiters (SFCLs) for active current limiting (peak prevention).

Solid state and SFCLs are advantageous in that the fault detection is inherent and does not require a complex trigger mechanism. However, the recovery time of different SFCL technologies vary ${ }^{20}$, and so the limitations on their use for successive faults must be assessed. They are a natural choice of protection device in a superconducting system. Since future electric propulsion aircraft may need to be superconducting in order to reach feasible system power densities, SFCLs may prove highly useful in reducing the maximum fault current rating of the other components so that the overall weight is reduced.

An excerpt of the data gathered on current SFCL projects is given in Table 2.

\section{Trade Space Mapping}

The data on available protection devices can be visually analysed to determine feasible protection devices, and hence possible fault management strategies. Trade space mapping involves plotting multiple aspects of system design in 3D space. The trade space can then illustrate the status or capability of certain protection devices within that 3D plot. Trends in the data (such as low TRL of a particular converter topology) can be identified. An example of trade space mapping of selected fault current limiter devices based on the data in Table 1 is shown in Figure 1:

\section{Developments in Fault Current Limiters}

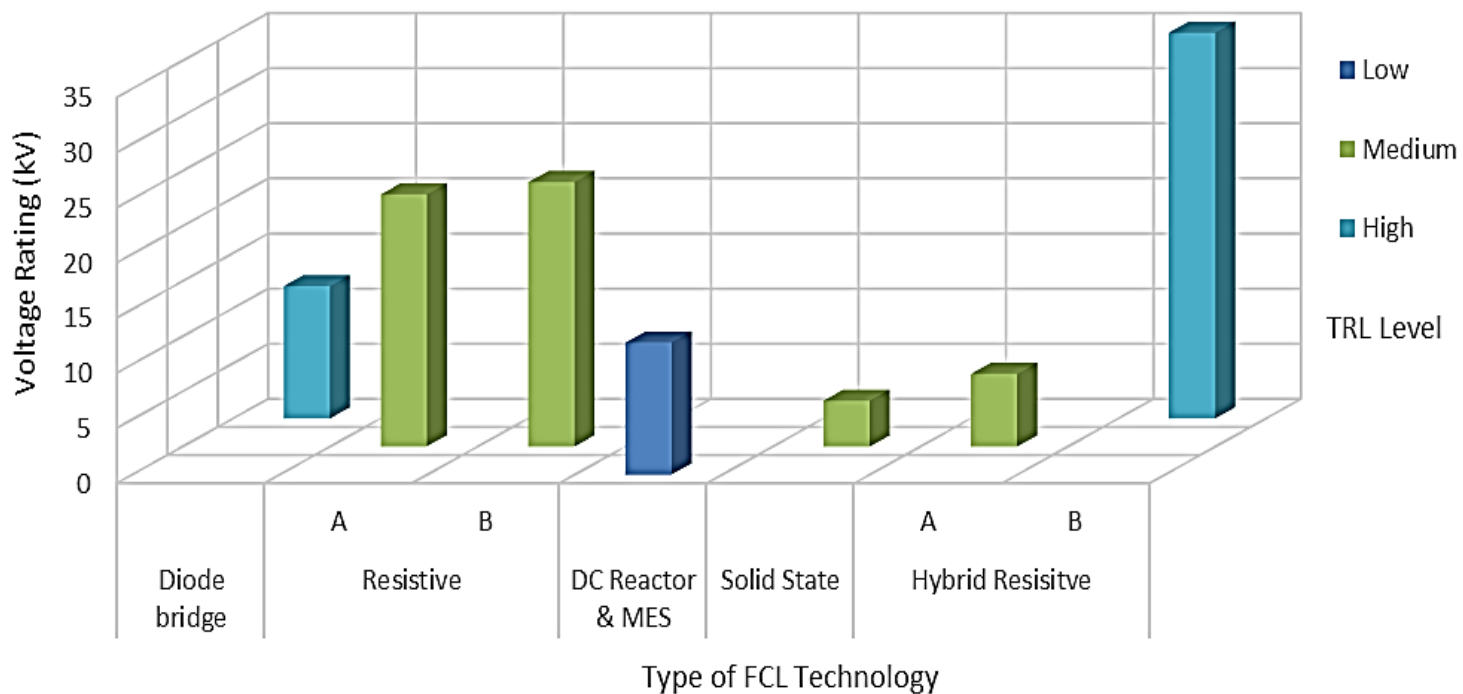

Figure 1: Example of 3D trade space showing voltage rating, technology and TRL level for various fault current limiters 


\section{Constraints}

In order to highlight feasible fault management strategies, the protection device trade space must consider the fact that all available devices will be subject to a number of constraints. Whilst there are many constraints that will influence the protection system design, it is important to emphasise those which are specific to an aircraft application (such as weight) as well as those which may be especially challenging, given the current status of protection technologies.

It is also important to highlight that these design limitations for a given aircraft are subject to change. The expected point of EIS for a hybrid aircraft may shift due to governmental pressure to reduce emissions from aircraft sooner, or may be pushed back where there are financial challenges within the industry or insufficient technology progress. For example, NASA delayed the expected EIS date of some of its developmental aircraft in $2016^{21}$, compared to previously released roadmaps. There may also be aspects of particular technologies (e.g. superconducting cables) whose constraints will become apparent in the future but are at the moment unknown. Thus the choice of protection devices which meet the design constraints is subject to a degree of uncertainty resulting from both known unknowns and unknown unknowns.

Although the specifications for a given future aircraft system may not yet be fully defined, it is possible to identify from the literature suitable ranges or a threshold value for a particular variable or aspect of design. This helps guide the selection of protection devices that could form part of a fault management strategy as options that are obviously unviable are eliminated early on, and focus is given to the most promising technologies. In this way, the feasible region for protection devices can be identified. Mapping of the constraints must also consider the fact that some constraints are variable between a small number discrete values (such as defined technology types), and some are variable across a wide range of values (such as operating time of DC breakers). Furthermore, as part of a process of performing trades between different FMS constraints it is possible to set some constraints to be constant and then others to vary. For example, this could involve defining TRL as high and selecting power converters as the technology type, and then varying the allowable power density and efficiencies. A graphical example of this application of constraints within the protection device trade space is shown in Figure 2.

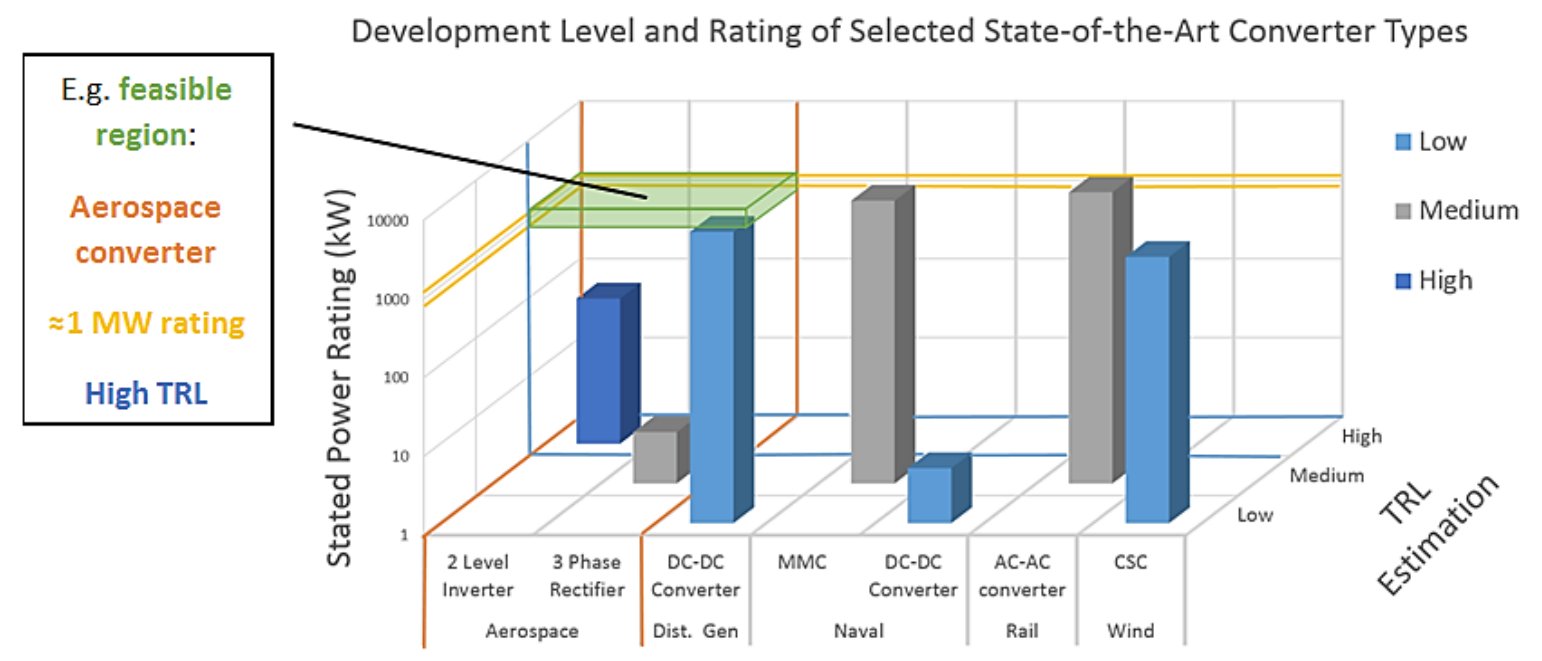

Converter Topology Type \& Application Area

Figure 2: Example of 3D trade space showing power rating, topology/ application and TRL level for stateof-the-art power converters

After each iteration of the design process as technology evolves and the constraints become better defined, the trade space can be updated until there are devices which exist in the feasible region. The feasible region can also be paralleled to the technology road map to define the feasible region for protection devices across a spectrum of potential aircraft technology selection dates. 


\section{A. Voltage and Power Ratings}

Two of the most immediate constraints are the system voltage and power ratings. Voltages on conventional aircraft have not yet matched increases in railway or naval system ratings and the existing standards for aero-electrical systems are only for lower voltage levels up to $270 \mathrm{Vdc}^{22}$. However, the probable shift from present aircraft systems rated at $115 \mathrm{~V}_{\mathrm{ac}},+/-270 \mathrm{~V}_{\mathrm{dc}}$ and $28 \mathrm{~V}_{\mathrm{dc}}{ }^{23}$ to $700 \mathrm{~V}$ in the medium term ${ }^{24}$, then to voltages in the $\mathrm{kV}$ range ${ }^{25,26}$ in order to supply high power propulsion loads with minimal losses is one of the key design factors that differentiates current protection systems and those of the future.

The voltage ranges for selected hybrid aircraft concepts described in the literature is given in Figure 3:

\section{Voltage Rating for Various Hybrid Aircraft Concepts}

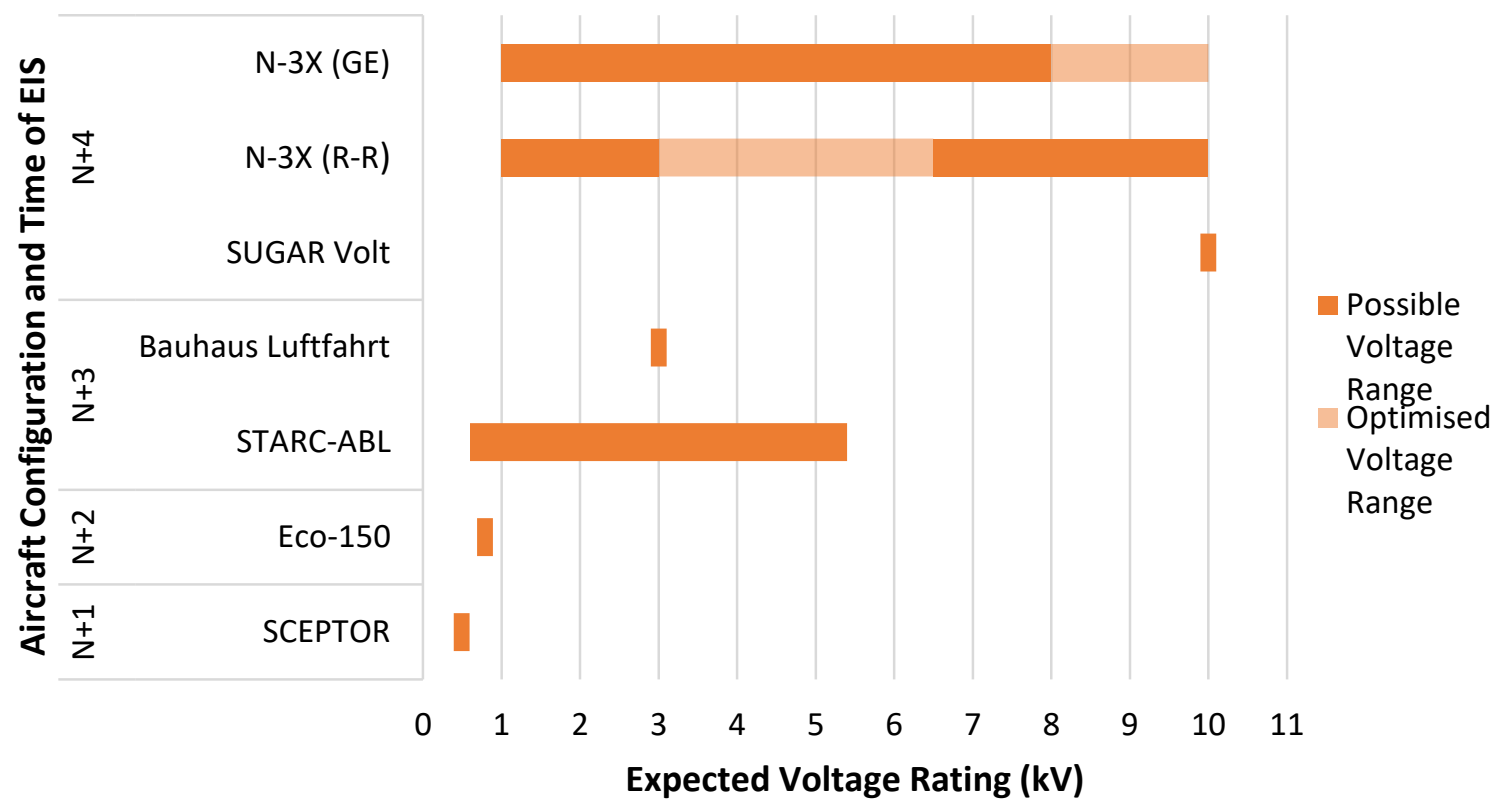

\section{Figure 3: Voltage Rating for Various Hybrid Aircraft Concepts}

The voltage data for Boeing's SUGAR Volt aircraft is taken from the input parameters to the system model ${ }^{27}$. The voltage rating of the bus bar is $10 \mathrm{kV}$ with the power converters rated for $500 \mathrm{~V}_{\mathrm{dc}}$ and $120 \mathrm{~V}_{\mathrm{ac}}$. As an electrical system architecture is not provided, so it is assumed that the protection devices for this aircraft should be rated for the bus bar voltage. Further work is needed to fully understand the electrical system which would support the propulsive motors and batteries in this design.

The STARC-ABL system was not defined for a specific voltage value, but rather was assessed over a range of voltages from current state-of-the-art aircraft levels to MV naval system ratings. Although the cables in this design were rated at $1000 \mathrm{~V}$, the protection devices were scaled for power densities at $6500 \mathrm{~V}^{28}$. Therefore, it is likely that the voltage range indicated in Figure 3 will be reduced or better defined based on trades between efficiency and system weight.

As mentioned already, the exact voltage ratings for an aircraft may not yet be decided, but reviewing the literature and the data in Figure 3 gives an indication of likely ranges $\left(1 \times 10^{3} \mathrm{~V}\right.$ range for superconducting systems, $1 \times 10^{2} \mathrm{~V}$ scale for nearer term ambient temperature aircraft).

\section{B. Weight Budget Constraint}

The weight budget constraint is particularly important as the weight of the protection system will form a nonnegligible component of the overall electrical system weight, especially if the system is superconducting due to the cooling system requirement ${ }^{29}$. A review of published hybrid electric aircraft literature reveals that there is little understanding of the impact of the protection system weight upon the feasibility of the overall electric system, since protection system weight is at times not included in aircraft weight breakdown figures ${ }^{26,27,30}$. Focus is in some cases instead given to the significance of battery weight and design sensitivities to battery improvements and availability. However, the protection system weight must also be given consideration at this design stage, in view of the need for security of power supply to the propulsors and the weight of current protection devices. 
It is anticipated that larger aircraft will require larger power systems and hence higher rated protection devices. Furthermore, the possible change in electrical configuration from conventional electrical systems to superconducting (STARC-ABL ${ }^{31} /$ Quadfan $^{26}$ to $\mathrm{N} 3-\mathrm{X}^{32,33}$ ) for larger aircraft implies an increase in total protection system weight. Published literature on Boeing's SUGAR Volt aircraft, BHL's Propulsive Fuselage aircraft and ESAero's Eco-150 aircraft heavily discussed aeronautical system design but did not state electrical system weight breakdown in sufficient detail for an effective comparison to be made. Therefore, as previously noted, there is a need for all proposed architectures to consider electrical protection devices before commencing more detailed system design, as this will shape other aspects of the electrical propulsion system and form a component of the maximum take-off weight.

\section{Component Power Density Constraint}

Power density of protection components is a significant constraint and important point of comparison between technologies. Aircraft concepts which are less developed and targeted towards the far term may not have a defined total system weight budget, and so it may be difficult to derive the weight constraint for individual components. In this case, the target component power densities are a useful metric to enable assessment of the feasibility of different technologies and to define the feasible region within the trade space. This bottom-up approach to quantifying constraints does overlap with the top-down approach based on the aircraft system level requirements, yet both are useful means of directing the choice of FMS towards a solution based on protection devices which fulfil the aircraft constraints.

At present the power density of silicon based power electronics for aircraft is around $2.2 \mathrm{~kW} / \mathrm{kg}^{4}$. Advances in silicon carbide $(\mathrm{SiC})$ switching devices are expected to increase the power density to $9 \mathrm{~kW} / \mathrm{kg}$ for aircraft power electronics applications by around $2035^{4}$. Yet this is still less than the $19 \mathrm{~kW} / \mathrm{kg}$ target for complete power converters on the N+3 NASA STARC-ABL aircraft, and the $13 \mathrm{~kW} / \mathrm{kg}$ for the N+1 SCEPTOR aircraft ${ }^{28}$. Raytheon have begun developing novel High Temperature Silicon Carbide power modules specifically targeted towards a More Electric Aircraft (MEA) power system ${ }^{34}$. Although the exact power densities of these devices are not yet published, this demonstrates that $\mathrm{SiC}$ power electronics are already being investigated as an enabling technology for future aircraft.

Moreover, Thales are developing Power Electronics Modules (PEMs) for MEA applications with a current power density of $2-3 \mathrm{~kW} / \mathrm{kg}$ for today's devices, $6 \mathrm{~kW} / \mathrm{kg}$ for next generation modules and ultimately $9-15 \mathrm{~kW} / \mathrm{kg}$ for N+2 devices $^{35}$. This is in a similar range as the values quoted about for NASA's SCEPTOR project and is further verified by the N+2 PEMs reaching TRL 5 in 2015 . The modularity of this design may be useful for scaling up these power converters for higher power rated systems.

Furthermore, a state-of-the art rectifier developed by ETH Zurich aimed at MEA applications achieved a power density of $9.44 \mathrm{~kW} / \mathrm{kg}$ and a volumetric power density of $14.1 \mathrm{~kW} / \mathrm{dm}^{3}$ rated for a $10 \mathrm{~kW}$ system ${ }^{36}$. Almost half (48\%) the total volume was derived from the EMI filter, which highlights the fact that the bulky filter components are an area in need of improvement for future power electronic devices. The rated voltage for this device was in the range of $320-480 \mathrm{~V}_{\mathrm{ac}}$, which is more suitable for powering electronic subsystem networks on hybrid aircraft as opposed to electric propulsion loads. However, if this power density could be scaled to the $\mathrm{kV}$ range, this would make AC-DC conversion with DC transmission more attractive.

\section{Automotive Converter Power Density}

Whilst advances in aircraft high power density converters have yet to be fully realised, the automotive industry has already seen an increase in power converter ratings for electric and hybrid vehicles over the last decade ${ }^{37}$. It is possible that a similar level of development could be achieved in aircraft power converters, if a similar level of investment is achieved. Furthermore, power electronics in Formula 1 electric vehicle systems also give an indication of technology improvements that might be possible, as this is an area of the automotive industry in which the constraints on weight and volume are particularly stringent, yet where there is funding and motivation to develop means of overcoming such challenges. One such example would be McLaren's Motor Control Unit (MCU) which contains a 14V DC-DC converter using SiC MOSFETS ${ }^{12}$ which offers greater power density (over $20 \mathrm{~kW} / \mathrm{kg}^{38}$ ) and reduced cooling requirements in comparison to previous models and is a market leader. This shows that $\mathrm{SiC}$ power electronics are already being exploited in automotive systems to increase efficiency and power density, which is a good indicator for potential success in aerospace applications.

\section{Power Density of SFCLs}

The current power density of SFCLs is very low, due to the fact that they are typically one-off installations on terrestrial grids used to protect critical sections of a network. The lowest weighted SFCL published in the Electric Power Research Institute Technology Review ${ }^{20}$ as of 2012 was $907 \mathrm{~kg}$ rated at $22.9 \mathrm{kV}$. If this weight were to be linearly scaled as a very basic metric for a $10 \mathrm{kV}$ aircraft system (such as the N-3X) then the expected weight would

American Institute of Aeronautics and Astronautics 
be in the region of $396 \mathrm{~kg}$. This significantly higher than the $2.8 \mathrm{~kg}$ weight of the $11.19 \mathrm{MW}$ rated SFCLs required for the cross redundant multi-feeder architecture suggested for the N-3X aircraft ${ }^{39}$.

However, the SFCLs installed currently on the grid must have their own cryogenic system, which adds to the overall weight. Devices on a superconducting aircraft would be able to benefit from weight savings due to a centralised cryogenic system supplying all the superconducting devices. Furthermore, SFCLs developed for aircraft would naturally have a reduced weight due to components being chosen specifically to minimise weight, which may not be the case in SFCL technology demonstrators. However, the reductions in SFCL weight which are required to increase power density ratings from $\approx 4 \mathrm{~kW} / \mathrm{kg}$ of TRL $5-6$ devices in 2013 to the $4000 \mathrm{~kW} / \mathrm{kg}$ mentioned in the same study ${ }^{39}$, imply that SFCLs are not likely to feature in any FMS for N+1 or N+2 aircraft. Whilst naval SFCLs currently under development ${ }^{40,41}$ are expected to reduce weight and volume compared to terrestrial systems, it is expected that this technology will need to be developed and demonstrated in naval systems before being adapted and further reduced in size for a hybrid aircraft.

This demonstrates the significant discrepancy in current technology development and desired target specifications. It is then worth noting that the weight constraint (the available protection device weight budget) may dictate that certain protection devices are simply unviable for a given aircraft entry into service.

\section{Power Density of MVDC Circuit Breakers}

Another weight sensitive design technology is MVDC circuit breakers. A comparison of protection system total weight and the projected weight of MVDC breakers across a number of hybrid aircraft concepts which specify this device as part of the electrical architecture is shown in Table 4, where the values are either from data in the literature or calculated from stated power densities of the protection equipment.

Table 4: Overview of total protection device weight for a selection of hybrid aircraft

\begin{tabular}{|l|l|l|l|l|l|}
\hline Aircraft & Developer & $\begin{array}{l}\text { Time } \\
\text { Frame }\end{array}$ & $\begin{array}{l}\text { Total Weight } \\
\text { of Protection } \\
\text { Devices }(\mathrm{kg})^{*}\end{array}$ & $\begin{array}{l}\text { Protection Devices on } \\
\text { Network }\end{array}$ & $\begin{array}{l}\text { Individual DC } \\
\text { Breaker Weight } \\
(\mathrm{kg})\end{array}$ \\
\hline SCEPTOR $^{28}$ & NASA & $\mathrm{N}+1$ & 3.8 & 10 DC circuit breakers & 0.4 \\
\hline $\begin{array}{l}\text { STARC- } \\
\text { ABL }^{28}\end{array}$ & NASA & $\mathrm{N}+3$ & 13.6 & 4 DC circuit breakers & 6.87 \\
\hline $\begin{array}{l}\text { Hybrid Quad- } \\
\text { fan }^{26}\end{array}$ & $\begin{array}{l}\text { Bauhaus } \\
\text { Luftfahrt }\end{array}$ & $\mathrm{N}+3$ & 252 & 5 SSPCs (DC) & $50.5^{\dagger}$ \\
\hline $\mathrm{N}-3 \mathrm{X}^{32}$ & $\begin{array}{l}\text { Rolls-Royce } \\
\text { and NASA }\end{array}$ & $\mathrm{N}+4$ & $5438^{\ddagger}$ & $\begin{array}{l}\text { 60 AC breakers, DC } \\
\text { breakers (18 high } \\
\text { power \& 128 low } \\
\text { power), 134 fault } \\
\text { current limiters }\end{array}$ & $62.5^{\S}$ \\
\hline $\mathrm{N}-3 \mathrm{X}^{33}$ & $\begin{array}{l}\text { GE and } \\
\text { NASA }\end{array}$ & $\mathrm{N}+4$ & $1237^{* *}$ & $\begin{array}{l}\text { 20 Hybrid AC } \\
\text { breakers, 20 Hybrid } \\
\text { DC breakers (16 low } \\
\text { power \& 4 higher } \\
\text { power), 68 disconnects }\end{array}$ & $71.84^{\dagger \dagger}$ \\
\hline
\end{tabular}

The DC circuit breakers which are employed in the X-57 SCEPTOR architecture will be current commercial devices since the plane is intended to begin flight testing in $2018^{42}$. This then provides an indication of what is currently feasible on a smaller scale than a single aisle passenger aircraft.

Although SSPCs form part of the architecture outlined in Table 4, they are not available rated at $3000 \mathrm{~V}$, and currently have a maximum rating of $270 \mathrm{~V}_{\mathrm{dc}}$ at $25 \mathrm{~A}^{43}$. Whilst a novel SSPC prototype for MEA systems operating at

${ }^{*}$ Does not include the converter weights

${ }^{\dagger}$ Based on $44 \mathrm{~kW} / \mathrm{kg}$ power density and $2220 \mathrm{~kW}$ electric propulsion power ${ }^{26}$, assuming SSPCs are rated for full motor power

* Weight for Multi-Feeder architecture base line weight ${ }^{32}$ (page 145 in reference)

$\S$ Based on a high power SSCB rated at $12.5 \mathrm{MW}$ and with a $200 \mathrm{~kW} / \mathrm{kg}$ expected power density

** Total protection weight for $8 \mathrm{kV}$ system to optimise overall weight, but individual DC breaker rated for $10 \mathrm{kV}$

${ }^{\dagger}$ Hybrid DC breaker scaled to $10 \mathrm{MW}$ rating

American Institute of Aeronautics and Astronautics 
$540 \mathrm{~V}_{\mathrm{dc}}$ has been demonstrated ${ }^{44}$, the assumption that $\mathrm{N}+3$ hybrid systems could utilise SSPCs for DC fault management is based on a very significant development in solid state switches suitable for SSPCs (in terms of V/I ratings and on-state losses) and on the energy dissipation capacity of the switch.

The remaining scenarios have stipulated a DC breaker power density of $200 \mathrm{~kW} / \mathrm{kg}$ which was identified in a recent NASA study as a best case scenario rating ${ }^{32}$. However, given that example solid state DC breakers of TRL 5-6 (verified in a relevant environment) had a power density of $14 \mathrm{~kW} / \mathrm{kg}$ in $2013^{39}$, this infers an increase in power density more than ten times the current level. Whilst some of this could be achieved by improvements in solid state switches, operation at higher power will demand greater cooling which may offset these improvements. At present, available IGBT silicon devices from Mitsubishi and Infineon have a maximum voltage blocking rating of $6.5 \mathrm{kV}$ and a maximum current rating of $1.5 \mathrm{kA}^{33}$, which means that these devices would not be suitable for use in current $\mathrm{N}-3 \mathrm{X}$ FMS designs.

Furthermore, Electro-Mechanical Circuit Breakers (EMCBs) may not be suitable for all future aircraft applications. For example, commercially available vacuum MVDC breakers from ABB rated at $12 \mathrm{kV}$ and nominal current $2 \mathrm{kA}$ have a weight of $121 \mathrm{~kg}$ and require between $33-60 \mathrm{~ms}$ to open in response to a fault ${ }^{45}$. Whilst this device is rated in similar voltage and current ranges for the N-3X aircraft, the speed of operation of the breaker may be too slow for compact low impedance aircraft networks, and the weight is almost certainly too large given the estimated target weight of $20-72 \mathrm{~kg}^{32,33}$.

\section{Alternatives to MVDC Circuit Breakers}

Therefore, while it is important to identify target values of power density, it must be understood that such ideals may not be realised in the chosen development time frame. Alternatives to DC breakers need to be sought in order to ensure that protection of DC distribution on aircraft can be achieved. One such alternative to both SSCBs and EMCBs are DC disconnect switches. These switches do not interrupt the fault current, but rather isolate a fault and allow reconfiguration of the network after the fault has been cleared by AC circuit breakers ${ }^{46}$. Thus the device must only interrupt small leakage currents in the order of $\mathrm{mA}$ which reduces both the volume and mass of the overall device. The weight of DC disconnects has been estimated as $6.49 \mathrm{~kg}$ for a $10 \mathrm{kV}, 10 \mathrm{MW}$ rated disconnect, which could be scaled with a power density rating of $1540 \mathrm{~kW} / \mathrm{kg}^{33}$. This power density is significantly higher than the current ratings of DC circuit breakers, and the weight is much less than the estimated DC breaker weight of $71.84 \mathrm{~kg}$ described in the same study. Although disconnects with a superconducting repulsive disc are still at low TRL, the possibility that some of the DC breakers on a network will be replaced by DC disconnects (or a similar non-current interrupting technology) in order to reduce the protection system weight has implications for the FMS as well as the architecture design, since greater sections of network must be de-energised during a fault clearing process ${ }^{47}$.

\section{Volume Constraint}

The volume of devices is also a concern, given the limited space which is available within the airframe. This is particularly pertinent for converter devices which may require large filtering components or insulation. For example, one DC-DC converter study highlighted that there was a volume utilisation of around 50\% in the converter, which was due to large isolation distances and material needed to achieve galvanic isolation ${ }^{48}$. Volume is also an important constraint in DC conventional circuit breakers since the components that stretch and extinguish the arc are bulky and contribute to the overall large volume of the device ${ }^{49}$. Solid state devices are an alternative; however, they are susceptible to higher conduction losses. Therefore, the constraints on the protection device trade space may influence the technology types which are feasible.

Secondly, protection devices must physically fit within the airframe. It is likely that the propulsion will be distributed, so the devices will have to be located in a variety of positions. Larger devices are more difficult to accommodate, especially where integration with novel aircraft configurations (such as Blended Wing Body or Double Bubble $^{50}$ ) is required.

American Institute of Aeronautics and Astronautics 


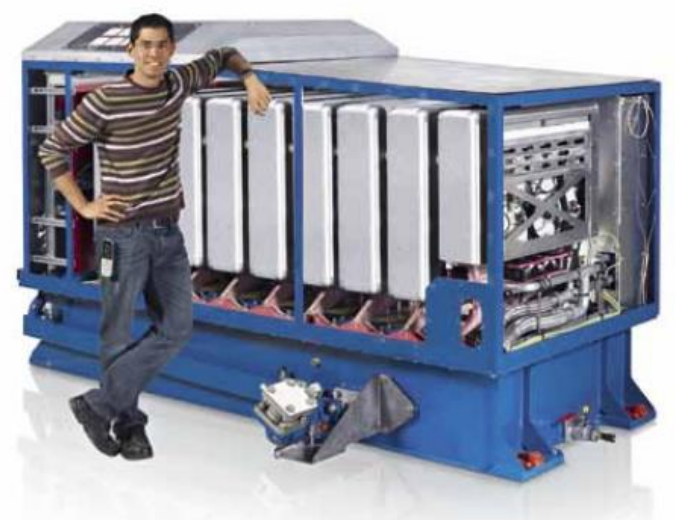

Figure 4: Transformer and rectifier device shown to indicate scale ${ }^{51}$

\section{Volume Constraint Case Study}

A recent prototype AC-DC-AC converter tested by ABB in a Swiss shunt locomotive was rated at $1.2 \mathrm{MW}$ although able to operate at a slightly higher level for a short time ${ }^{51}$. The device has a weight of $4500 \mathrm{~kg}$ and the scale is evident from Figure 4. This highlights the discrepancy between the current status of converters rated around $1 \mathrm{MW}$, and the reduction in scale that would be required in order to transfer this technology to an aircraft application. Furthermore, the cooling of this device benefits from the natural convection of the train draft which would not be possible on a pressurised aircraft, which implies that an alternative cooling mechanism would be appropriate. This example shows some of the complexity which can arise in transferring technology across application areas.

\section{E. Availability}

The database also provides a means to assess the current availability of different technology types. Regardless of the chosen electrical architecture, the protection system is fundamentally constrained by the availability of technology. Devices must be certified for use on an aircraft at the point where the aircraft and its subsystems are defined ahead of the EIS or they cannot be part of the fault management strategy. In pursuing novel protection devices, there is a risk that the technologies may not reach maturity within the required time frame or may have limits on their level of certification. Given the risk adverse nature of the aerospace industry, there is also the possibility that air framers may be reluctant to adopt technology that has not demonstrated long term reliability in an aircraft environment. Also, devices may theoretically be commercially available, yet the cost or complexity in manufacturing may entail that there is a limit on the number of units which can feasibly be used on an aircraft. Therefore, it is possible that the TRL of a given device may render it available from the electrical system design perspective, yet the aerospace industry may choose not to employ such a technology.

A comparison of current protection technology and the range of devices which are required to be available at the $\mathrm{N}+3$ to $\mathrm{N}+4$ time frames are shown in Table 5: 
Table 5: Current technology availability and desired protection devices for $\mathrm{N}+3$ and $\mathrm{N}+4$ aircraft

\begin{tabular}{|l|l|l|}
\hline Aspect of FMS & Current Technology & $\begin{array}{l}\text { Desired Technology in N+3/ N+4 } \\
\text { Timeframe }\end{array}$ \\
\hline $\begin{array}{l}\text { Fault Current } \\
\text { Interruption }\end{array}$ & $\begin{array}{l}\text { LVAC breakers } \\
\text { LVDC breakers } \\
\text { SSPCs }\end{array}$ & $\begin{array}{l}\text { MVDC SSCBs } \\
\text { MW Rated controlled power } \\
\text { converters }\end{array}$ \\
\hline $\begin{array}{l}\text { Maximum Fault } \\
\text { Current Reduction }\end{array}$ & $\begin{array}{l}\text { Fuses } \\
\text { Generator Circuit Breaker (GCB })^{82}\end{array}$ & $\begin{array}{l}\text { MW Rated controlled power } \\
\text { converters }^{83,25} \\
\text { Fault current limiting breaker }\end{array}$ \\
& & $\begin{array}{l}\text { Fast differential protection } \\
\text { SFCL,56 }\end{array}$ \\
\hline $\begin{array}{l}\text { Network } \\
\text { Reconfiguration }\end{array}$ & $\begin{array}{l}\text { MVDC bus ties } \\
\text { BS tie breakers (BTB })^{87} \\
\text { SSPCs }\end{array}$ & $\begin{array}{l}\text { MVDC breakers } \\
\text { MVAC breakers } \\
\text { MVDC disconnects }\end{array}$ \\
\hline
\end{tabular}

As shown in Table 5, there is a much larger range of protection devices that are desired for longer term aircraft configurations, in order to support the increased flexibility, complexity and power ratings of the network. Although SFCLs are installed in a number of terrestrial grids, superconductivity is considered an N+4 technology for aircraft ${ }^{4}$ and so devices such as SFCLs and superconducting repulsive disc disconnects ${ }^{33}$ are unlikely to be commercially available before then. It is also worth noting the increased use of converters as part of an FMS. The exact functionality of these devices within an FMS is dependent on the topology and location on the network, and their feasibility depends on the converters reaching higher power densities.

The data in Table 5 is not inclusive of $\mathrm{N}+1$ or $\mathrm{N}+2$ electrical propulsion systems. This is due to the limited publications detailing electrical propulsion systems which relate to this development time frame. NASA's SBIR contracts with ESAero ${ }^{52}$ have considered electrical machine ratings and the impact of battery weight, as well as the feasibility of ambient temperature distributed electrical propulsion ${ }^{30}$. However, a detailed description and evaluation of the electrical network and particularly the protection devices were not within the scope of that study. The protection devices would have to operate at $700 \mathrm{~V}$ and the motor rating is $170 \mathrm{~kW}$, but the converter or circuit breaker ratings are not given. As the weight of the protection devices for electrical propulsion aircraft is non-negligible (and the study itself states that the transformers would be too large for this application), an accurate assessment of the FMS viability is required in order to ensure that the basic electrical system described is feasible for the development timeframe available.

\section{MVAC Breakers Availability}

AC breakers are an established technology which are already in use on conventional aircraft ${ }^{53}$, as well across other applications such as naval systems where AC transmission is in use. Therefore, it is anticipated that it will comparatively less challenging (compared to DC breakers) to source AC breakers of suitable rating and power density for hybrid propulsion aircraft, and indeed, published TeDP (Turboelectric Distributed Propulsion) electrical architectures utilise AC breakers at both the generator and motor sides of the network ${ }^{54}$.

\section{MVDC breakers availability}

MVDC breakers, however, are far more challenging to realise on a future aircraft. This is due to the fact that in order to interrupt the power flow in the high power density circuit, the current needs to be reduced to zero. AC circuits exhibit inherent zero crossing behaviour, which allows physical disconnection of the circuit at the point of zero current. In DC breakers this is of course not possible, which means that additional circuit complexity must be incorporated to deliver a near zero current. Existing methods used to achieve disconnection and energy dissipation, some of which involve arc chutes, others requiring large capacitors and inductors to create a resonant circuit, are typically bulky ${ }^{15}$ and may not be suitable for high power density systems. 


\section{MVDC Breaker Case study}

State-of-the-art naval and marine power system designs have increasingly employed DC power, which has led to a growing need for suitable DC breakers. In order to support the use of a DC bus supplying multiple high power AC drives, Siemens developed a method of splitting sections of the network to minimise the impact of short circuits. The IGBT bus circuit breaker (called "Integrated Load Controller") is capable of $<20 \mu$ s interrupt time, trips at $7 \mathrm{kA}$, is rated for $930 \mathrm{~V}_{\mathrm{dc}}$ and has a recovery time of $10 \mathrm{~ms}$ after a short circuit has occurred ${ }^{55}$. Since this technology has reached high TRL (already been implemented on first operational vessels) ${ }^{56}$ and is capable of very fast response to MVDC faults, this may be a device that has potential cross-over to a future aircraft application. Another aspect of this use of a differential protection mechanism is that the device reacts to high di/dt on the bus, meaning that the fault is isolated before maximum fault current is reached which would also be advantageous for a hybrid aircraft system.

\section{F. Altitude Constraint}

Another major challenge for the safe operation of electrical aircraft systems is the impact of high altitude on component operation. Aircraft systems have traditionally been limited by Paschen's law which describes the breakdown voltage of air at high altitudes ${ }^{57}$. However, with much higher propulsive electrical loads it is likely that the voltage rating will be above this conventional limit. Novel protection devices which have been developed for other applications will not have been proven at high altitude, and so it is unclear what effect this may have on the insulation requirements of the system. It is advantageous, therefore, to develop aero-specific protection devices from the outset and to begin to understand the complexities introduced to a fault management strategy as a result of operating at higher voltages in an aircraft environment subject to vibrations and variations in temperature and pressure.

\section{G. Thermal Constraints}

The required thermal management system for a chosen aero-electrical power system may have significant negative impact on performance (weight and efficiency) ${ }^{58}$. There may also be a limitation on where devices can be located if there is risk of the heat transfer from devices interfering with or causing damage to surrounding components. The cooling load for SFCLs or other superconducting devices constrains the system as a sufficient coolant mass flow rate must be maintained. Thermal losses from protection devices lower the efficiency so constraints on the maximum allowable heat transfer may apply. If batteries are to be used on the electrical network, then there may also be an optimal temperature for the environment surrounding the battery which would also pose a potential thermal constraint.

\section{H. Combination of Devices}

Thus far, protection devices have been discussed individually, yet there are advantages to be gained by combining different types of devices, such as greater redundancy and more flexible reconfiguration. However, there are trades to be made between the increased security of supply gained from the use of multiple devices on a section of network against the weight and efficiency penalty associated with increasing the number of devices. For example, reducing the maximum fault current rating for circuit breakers and cables by the addition of fault current limiters to the network ${ }^{47}$. Thus, the use of multiple, varied devices may lessen the impact of some constraints (maximum fault current in this case) yet makes other aspects of the FMS more difficult to achieve (minimal total weight). Therefore, the development of the FMS must consider the full electrical system in order to fully optimise the overall system efficiency.

\section{Mapping of Constraints Interdependency}

In the first instance, it is important to identify the main constraints on the design of the FMS for a given system. However, as each constraint impacts on other constraints and design considerations it is necessary to understand the interdependencies between constraints. By mapping out the connections between different constraints the relative criticality of each can be weighted. This enables constraints to be ranked according to which are the most critical for a given system. In this way the FMS is shaped by the most challenging constraints and the effect of any changes in constraints over time can be anticipated.

In order to demonstrate how this method of constraint mapping can be applied to the design of a future aircraft FMS, the following example is given using a selection of constraints. A number of likely constraints for an aircraft system are shown in

Figure 5. There are many more constraints not included in this example that would be considered for a complete FMS, however the constraints identified here are all of the "first order". Future work would involve classifying constraints as first or second order. It could also be argued that almost every constraint impacts on the others in some way, so it should be emphasised that at this point in the process the focus is to clarify the most crucial connections between

American Institute of Aeronautics and Astronautics 
constraints in order to simplify and direct the choice of FMS for a given system. Furthermore, choosing the most relevant constraints at this point is not necessarily straight forward, particularly due to the number of unknowns at this stage and the relatively low TRL of some of the protection technologies. However, these initial constraints have been identified from reviewing the aircraft and protection system requirements.

\section{A. Constraint Dependency Example}

If the constraint "Maximum Allowable Thrust Loss" is taken as an example, then it can be seen that there are a number of possible interdependencies between this constraint and the other selected constraints shown in the diagram. This can be explained as follows:

- Maximum allowable thrust loss for the aircraft is likely to be defined by safety standards, but also linked to the certification of the aircraft ${ }^{59}$.

- The impact of loss of power to the motors (leading to loss of thrust) will also depend on how quickly the protection system can respond to a fault and reconfigure power flow. This in turn is subject to redundant power being installed on the system and whether or not the network architecture enables this power to be delivered to any remaining motors.

- The power rating of the motors is also dependent on the allowable loss of thrust as if motors are overrated then loss of thrust due to fault at a single motor may be reduced, if the remaining generation capacity is sufficient.

In this way it is possible to identify key relationships between protection constraints as well as any sensitivities to changes to the design criteria.

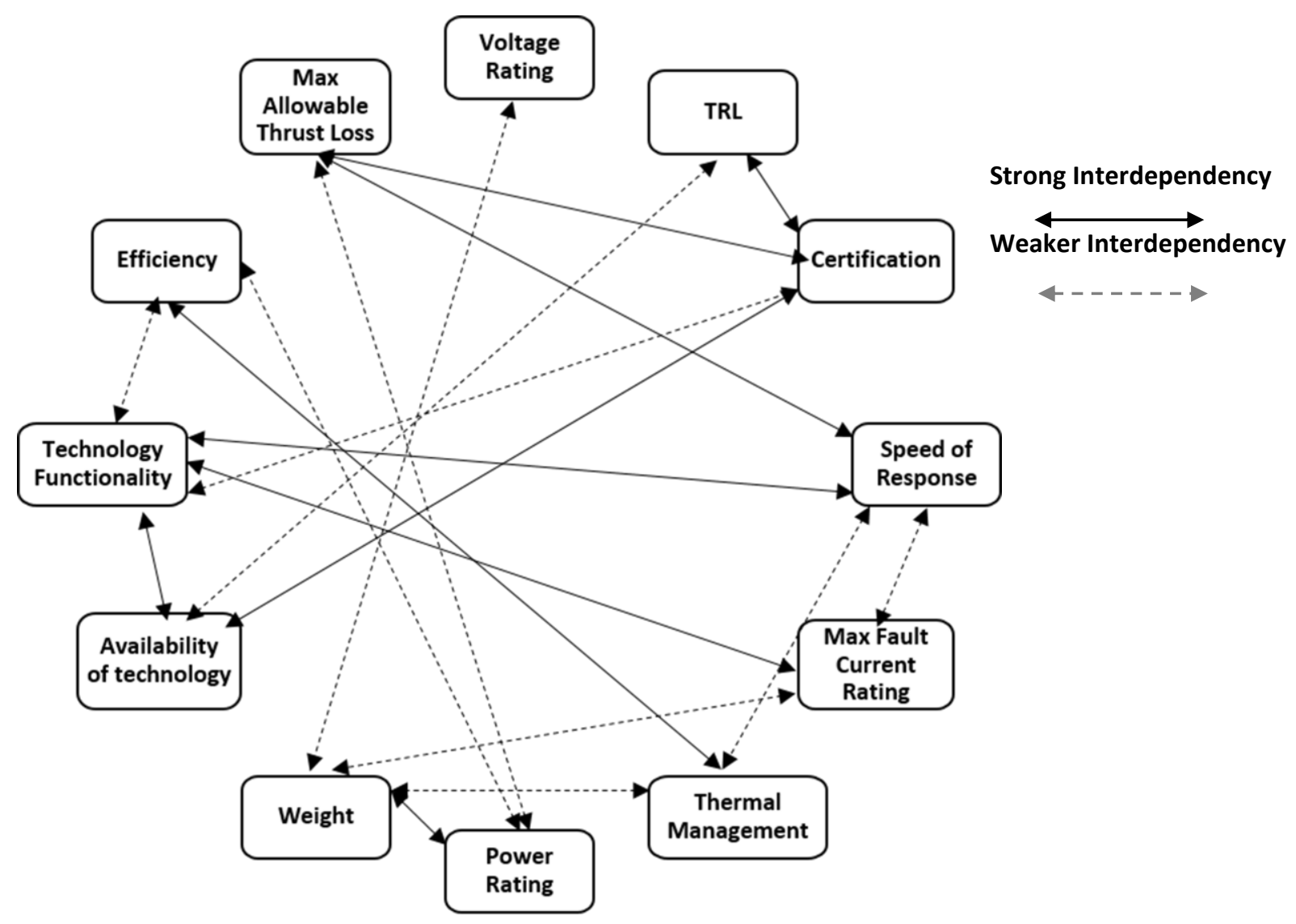

Figure 5: Constraint mapping 


\section{B. Selection of Most Important Constraint}

Once the key constraints have been identified from reviewing the aircraft requirements and the interdependencies have been mapped, the next stage is to ascertain the most important constraint (MIC). A constraint may be selected as the MIC based on a variety of factors such as technology limitations/progress, number of interlinked constraints and commercial innovation opportunities.

Since the design of the FMS for a future electrical propulsion aircraft is subject to many complex constraints, ranking the constraints in terms of criticality enables the selection of a single, important constraint. Thereafter, the choice of protection devices, FMS and ultimately network architecture will be defined in the first instance by the need to meet this constraint. By iterating this process, it is possible that an alternative MIC may be adopted, or that the MIC will vary depending on the aircraft developmental timeline.

\section{Target Weight Budget as MIC}

Based on the protection device database and initial trade space mapping, the MIC for the design of protection on electrical propulsion aircraft is likely to be the target weight budget. Whilst weight could be considered as a component level constraint or a systems level target, the available weight budget for aircraft with later points of EIS is a hard limit which has implications for the choice of FMS. The weight budget as a constraint is therefore useful in eliminating unviable FMSs at an early point in the design process. Furthermore, reduction in weight is the main goal which must be achieved before technologies developed for other applications can be transferred to an aircraft system. Weight is also one of the most challenging constraints to physically implement as typically improvements made to system performance or reliability lead to an addition of weight. This is made yet more difficult by the increasing power levels in aircraft, resulting in the situation where the weight must reduce while the system power ratings increase. Fundamentally, the fact remains that electrical propulsion aircraft have been pursued as a means to reduce aircraft emissions and this can only be achieved where the effect of adding electrical propulsion is offset by a reduction in fuel burn. Therefore, it is clear that on the one hand the weight of the electrical system must be minimised as far as possible, and on the other the FMS must be reliable, robust and contend with a large variety of complex constraints.

\section{Conclusion}

In conclusion, it is evident that the protection devices employed on an electrical propulsion aircraft form a crucial part of the system design. The availability, TRL and range of capability of protection devices at an aircraft's point of final electrical design will have a significant impact on the feasible fault management strategies, and hence the available electrical architectures. The protection device trade space highlights the fact that further development of current technologies, as well as innovative concepts, are needed before there are a range of established devices which are feasible for future aircraft. The constraints surrounding the design of an electrical propulsion protection system are demanding, particularly in regard to those which are specific to aero electrical systems (such as weight), and prioritising the correct constraints in order to achieve an optimised system design is not straight forward. Furthermore, this paper has shown that the interdependencies between constraints can be assessed even before the architecture is decided, which allows the impact of variations in the range or rating of a particular constraint to be understood. In light of these constraints and the requirement for high reliability of the whole electrical system, it is imperative that the protection system is considered from the outset to ensure the viability of the chosen FMS. Therefore, by applying a process of electrical network design that is driven by the protection requirements, constrained by the relevant system limitations and informed by the available protection devices, the most optimal electrical power system architecture can be achieved.

\section{Acknowledgments}

This work was carried out as part of the Rolls-Royce University Technology Centre programme.

\section{References}

International Civil Aviation Organization, "Forecasts of Scheduled Passenger and Freight Traffic," International Civil Aviation Organization Available: http://www.icao.int/sustainability/pages/eap_fp_forecastmed.aspx.

2 Berg, F., Palmer, J., Miller, P., Husband, M., and Dodds, G., "HTS Electrical System for a Distributed Propulsion Aircraft," IEEE Transactions on Applied Superconductivity, vol. 25, 2015, pp. 1-5.

3 Davies, K. M., Norman, P. J., Jones, C. E., Galloway, S. J., and Burt, G. M., "Fault behaviour of a superconducting turboelectric distributed propulsion aircraft network: A comprehensive sensitivity study," 2015 International Conference on Electrical Systems for Aircraft, Railway, Ship Propulsion and Road Vehicles (ESARS), Aachen: IEEE, 2015, pp. 1-6. 
Committee on Propulsion and Energy Systems to Reduce Commercial Aviation Carbon Emissions, "Commercial Aircraft Propulsion and Energy Systems Research: Reducing Global Carbon Emissions," The National Academies Press Available: https://www.nap.edu/read/23490/chapter/4.

Mai, T., "Technology Readiness Level" Available: https://www.nasa.gov/directorates/heo/scan/engineering/technology/txt_accordion1.html.

Adam, G. P., Gowaid, I. A., Finney, S. J., Williams, B. W., and Holliday, D., "Review of dc-dc converters for multiterminal HVDC transmission networks," IET Power Electronics, vol. 9, Feb. 2016, pp. 281-296.

Müller, H. K., Torbaghan, S. S., Gibescu, M., Roggenkamp, M. M., and van der Meijden, M. A. M. M., "The need for a common standard for voltage levels of HVDC VSC technology," Energy Policy, vol. 63, 2013, pp. 244-251.

Moriconi, F., De La Rosa, F., Darmann, F., Nelson, A., and Masur, L., "Development and Deployment of Saturated-Core Fault Current Limiters in Distribution and Transmission Substations," IEEE Transactions on Applied Superconductivity, vol. 21, Jun. 2011, pp. 1288-1293.

David Klaus, Chris Waller, Darren Jones, Jamie McWilliam, Jonathan Berry, Joachim Bock, Joseph Helm, Mostafa Jafarnia, and Achim Hobl, "Superconducting Fault Current Limiters - UK Network Trials Live and Limiting," 22nd International Conference on Electricity Distribution, 2013, p. 2085.

Muscas, C., Pau, M., Pegoraro, P., and Sulis, S., "Smart electric energy measurements in power distribution grids," IEEE Instrumentation \& Measurement Magazine, vol. 18, Feb. 2015, pp. 17-21.

Doerry, N., and Moniri, K., "Specifications and standards for the electric warship," 2013 IEEE Electric Ship Technologies Symposium (ESTS), IEEE, 2013, pp. 21-28.

McLaren Applied Technologies, "High Performance Electric Motors and Drives," McLaren Available: http://www.mclaren.com/appliedtechnologies/case-study/relentless-drive-power-density-and-efficiency.

Jimi Beckwith, "London Taxi Company's electrified cab to hit the road this year | Autocar," Autocar Available: https://www.autocar.co.uk/car-news/new-cars/london-taxi-companys-electrified-cab-hit-road-year.

Graham, W. R., Hall, C. A., and Vera Morales, M., "The potential of future aircraft technology for noise and pollutant emissions reduction," Transport Policy, vol. 34, 2014, pp. 36-51.

Electric Ship Research and Development Consortium, and for the Office of Naval Research, DC Protection, 2011.

Cuzner, R., and Jeutter, A., "DC zonal electrical system fault isolation and reconfiguration," 2009 IEEE Electric Ship Technologies Symposium, IEEE, 2009, pp. 227-234.

Sun, K., Soto, D., Steurer, M., and Faruque, M. O., "Experimental verification of limiting fault currents in MVDC systems by using modular multilevel converters," 2015 IEEE Electric Ship Technologies Symposium (ESTS), 2015, pp. 27-33.

Steurer, M., Bogdan, F., Bosworth, M., Faruque, O., Hauer, J., Schoder, K., Sloderbeck, M., Soto, D., Sun, K., Winkelnkemper, M., Schwager, L., and Blaszczyk, P., "Multifunctional megawatt scale medium voltage DC test bed based on modular multilevel converter (MMC) technology," 2015 International Conference on Electrical Systems for Aircraft, Railway, Ship Propulsion and Road Vehicles (ESARS), IEEE, 2015, pp. 1-6.

Xue, S., Gao, F., Sun, W., and Li, B., "Protection Principle for a DC Distribution System with a Resistive Superconductive Fault Current Limiter," Energies, vol. 8, 2015, pp. 4839-4852.

EPRI, Superconducting Power Equipment: Technology Watch 2012, California: 2012.

Esker, B., "ARMD Strategic Thrust 4: Transition to Low-Carbon Propulsion" Available: https://www.nasa.gov/sites/default/files/atoms/files/armd-sip-thrust-4-508.pdf.

US Department of Defence, "MIL-STD-704F Aircraft Electric Power Characteristics" Available: https://prod.nais.nasa.gov/eps/eps_data/137899-SOL-001-015.pdf.

Nya, B. H., Brombach, J., and Schulz, D., "Benefits of higher voltage levels in aircraft electrical power systems," 2012 Electrical Systems for Aircraft, Railway and Ship Propulsion, IEEE, 2012, pp. 1-5.

Benjamin Schiltgen, Andrew R. Gibson, Michael Green, and Jeffrey Freeman, "More Electric Aircraft: 'Tube and Wing' Hybrid Electric Distributed Propulsion with Superconducting and Conventional Electric Machines," SAE Technical Paper, vol. 2013-01-23, 2013.

Jones, C. E., Davies, K., Norman, P., Galloway, S., Burt, G., Armstrong, M., and Bollman, A., "Protection System Considerations for DC Distributed Electrical Propulsion Systems," 2015.

Pornet, C., and Isikveren, A. T., "Conceptual design of hybrid-electric transport aircraft," Progress in Aerospace Sciences, vol. 79, 2015, pp. 114-135.

Bradley, M. K., and Droney, C. K., Subsonic Ultra Green Aircraft Research: Phase II - Volume II - Hybrid Electric Design Exploration, California: 2015.

Jansen, R. H., Bowman, C., and Jankovsky, A., "Sizing Power Components of an Electrically Driven Tail Cone Thruster and a Range Extender," 16th AIAA Aviation Technology, Integration, and Operations Conference, AIAA AVIATION Forum, AIAA, 2016, p. AIAA 2016-3766.

Jones, C. E., Davies, K., Norman, P., Galloway, S., Burt, G., Armstrong, M., and Bollman, A., "Protection System Considerations for DC Distributed Electrical Propulsion Systems Protection for TeDP Network," SAE Technical Paper, 2015, pp. 2015-01-2404.

Gibson, A. R., Hall, D., Waters, M., Schiltgen, B., Foster, T., Keith, J., and Masson, P., "The Potential and Challenge of TurboElectric Propulsion for Subsonic Transport Aircraft," 48th AIAA Aerospace Sciences Meeting Including the New Horizons Forum and Aerospace Exposition, Orlando, Florida: 2010, p. AIAA 2010-276.

Jansen, R., Bowman, C., and Jankovsky, A., "Sizing Power Components of an Electrically Driven Tail Cone Thruster and 
a Range Extender," 16th AIAA Aviation Technology, Integration, and Operations Conference, Reston, Virginia: American Institute of Aeronautics and Astronautics, 2016. and Components for a Turboelectric Distributed Propulsion Electric Grid (AVC-TeDP), Rolls-Royce North American Technologies, 2015.

Gemin, P., Kupiszewski, T., Radun, A., Pan, Y., and Lai, R., Architecture, Voltage and Components for a Turboelectric Distributed Propulsion Electric Grid ( AVC-TeDP ), Cleveland, Ohio: 2015.

Raytheon, "Meeting the More Electric Aircraft Challenge," Raytheon Press Release Available: http://www.raytheon.com/news/rtnwcm/groups/gallery/documents/content/rtn_164022.pdf.

Thalin, P., "Overview of challenges in active power conversion for the More Electric Aircraft," Electrical Technologies for the Aviation of the Future, Europe-Japan Symposium, Tokyo: SUNJET Project, 2015. Hartmann, M., "Ultra-Compact and Ultra-Efficient Three-Phase PWM Rectifier Systems for More Electric Aircraft," ETH Zurich, 2011.

American Institute of Aeronautics and Astronautics 
EASA, "AMC-20 Amendment 7 - Annex II AMC 20-6 rev. 2" Available: https://www.easa.europa.eu/system/files/dfu/Annex II - AMC 20-6.pdf. Krstic, S., Wellner, E. L., Bendre, A. R., and Semenov, B., "Circuit Breaker Technologies for Advanced Ship Power Systems,” 2007 IEEE Electric Ship Technologies Symposium, Arlington, VA: IEEE, 2007, pp. 201-208. Zhenxue Xu, Bin Zhang, Sirisukprasert, S., Xigen Zhou, and Huang, A. Q., "The emitter turn-off thyristor-based DC circuit breaker," 2002 IEEE Power Engineering Society Winter Meeting. Conference Proceedings (Cat. No.02CH37309), IEEE, , pp. 288-293.

Meyer, J. M., and Rufer, A., "A DC hybrid circuit breaker with ultra-fast contact opening and integrated gate-commutated thyristors (IGCTs)," IEEE Transactions on Power Delivery, vol. 21, 2006, pp. 646-651.

Ahmed, M. M. R., Putrus, G. A., Ran, L., and Penlington, R., "Development of a Prototype Solid-State Fault-Current Limiting and Interrupting Device for Low-Voltage Distribution Networks," IEEE Transactions on Power Delivery, vol. 21, Oct. 2006, pp. 1997-2005.

Callavik, M., Blomberg, A., Häfner, J., and Jacobson, B., "The Hybrid HVDC Breaker An innovation breakthrough enabling reliable HVDC grids," ABB Grid Systems, Technical Paper Available: http://new.abb.com/docs/defaultsource/default-document-library/hybrid-hvdc-breaker---an-innovation-breakthrough-for-reliable-hvdcgridsnov2012finmc20121210_clean.pdf?sfvrsn=2. Michael Steurer, "Ein hybrides Schaltsystem für Mittelspannung zur strombegrenzenden Kurzschlussunterbrechung," PhD Thesis Available: http://e-collection.library.ethz.ch/eserv/eth:23871/eth-23871-02.pdf.

Kempkes, M., Roth, I., and Gaudreau, M., "Solid-state circuit breakers for Medium Voltage DC power," 2011 IEEE Electric Ship Technologies Symposium, Alexandria, VA: IEEE, 2011, pp. 254-257.

Corzine, K. A., and Ashton, R. W., "A new z-source dc circuit breaker," 2010 IEEE International Symposium on Industrial Electronics, Bari: IEEE, 2010, pp. 585-590.

Prempraneerach, P., Karniadakis, G. E., and Chryssostomidis, C., "DC Fault Protection in Shipboard Power Systems Using Z-Source Breakers," Sea Grant College Program Available: https://seagrant.mit.edu/ESRDC_library/MITSG_1130.pdf.

Glinka, M., and Marquardt, R., "A New AC/AC Multilevel Converter Family," IEEE Transactions on Industrial Electronics, vol. 52, Jun. 2005, pp. 662-669.

Lee, S.-H., Song, S.-G., Park, S.-J., Moon, C.-J., and Lee, M.-H., "Grid-connected photovoltaic system using currentsource inverter," Solar Energy, vol. 82, 2008, pp. 411-419.

71 Spichartz, M., Heising, C., Staudt, V., and Steimel, A., "State control of MMC-fed ship propulsion induction machine," 2013 IEEE Electric Ship Technologies Symposium (ESTS), IEEE, 2013, pp. 173-177. Jovcic, D., "Bidirectional, High-Power DC Transformer," IEEE Transactions on Power Delivery, vol. 24, Oct. 2009, pp. 2276-2283.

Zheng Wang, Ming Cheng, and K.T. Chau, "A current source converter fed high power wind energy conversion system with superconducting magnetic storage system in DC link," International Conference on Electrical Machines and Systems (ICEMS), Incheon, Korea (South): IEEE, 2010.

Yuan, X., Tekletsadik, K., Kovalsky, L., Bock, J., Breuer, F., and Elschner, S., "Proof-of-Concept Prototype Test Results of a Superconducting Fault Current Limiter for Transmission-Level Applications," IEEE Transactions on Appiled Superconductivity, vol. 15, Jun. 2005, pp. 1982-1985.

Hui, D., Wang, Z. K., Zhang, J. Y., Zhang, D., Dai, S. T., Zhao, C. H., Zhu, Z. Q., Li, H. D., Zhang, Z. F., Guan, Y., Xiao, L. Y., Lin, L. Z., Li, L. F., Gong, L. H., Xu, X. D., Lu, J. Z., Fang, Z., Zhang, H. X., Zeng, J. P., Li, G. P., and Zhou, S. Z., "Development and Test of $10.5 \mathrm{kV} / 1.5 \mathrm{kA}$ HTS Fault Current Limiter," IEEE Transactions on Applied Superconductivity, vol. 16, Jun. 2006, pp. 687-690.

Deo, P. R., Shah, T. P., and Chong, R., "Ambient-temperature fault current limiter for electric ship power systems," 2011 IEEE Electric Ship Technologies Symposium, 2011, pp. 223-227. Electric Power Research Institute;, "Superconducting Fault Current Limiters Technology Watch 2009" Available: https://www.epri.com/\#/pages/product/000000000001017793/.

78 Hyoungku Kang, Chanjoo Lee, Kwanwoo Nam, Yong Soo Yoon, Ho-Myung Chang, Tae Kuk Ko, and Bok-Yeol Seok, "Development of a 13.2 kV/630 A (8.3 MVA) High Temperature Superconducting Fault Current Limiter," IEEE Transactions on Applied Superconductivity, vol. 18, Jun. 2008, pp. 628-631.

79 Malozemoff, A. P., Fleshle, S., Rupich, M., Thieme, C., Li, X., Zhang, W., Otto, A., Maguire, J., Folts, D., Yuan, J., Kraemer, H.-P., Schmidt, W., Wohlfart, M., and Neumueller, H.-W., "Progress in high temperature superconductor coated conductors and their applications," Supercond. Sci. Technol. Supercond. Sci. Technol, vol. 21, 2008, pp. 34005-7. Moscrop, J. W., Darmann, F., and Moscrop, J., "Design and development of a 3-Phase saturated core high temperature superconducting fault current limiter," International Conference on Electric Power and Energy Conversion Systems, IEEE, 2009.

81 Yazawa, T., Koyanagi, K., Takahashi, M., Ono, M., Sakai, M., Toba, K., Takigami, H., Urata, M., Iijima, Y., Saitoh, T., Amemiya, N., and Shiohara, Y., "Design and Experimental Results of Three-Phase Superconducting Fault Current Limiter Using Highly-Resistive YBCO Tapes," IEEE Transactions on Applied Superconductivity, vol. 19, Jun. 2009, pp. 19561959.

82 Air Accidents Investigation Branch, “Air Accidents Investigation Branch Department for Transport Report on the serious incident to Airbus A319-111, registration G-EZAC near Nantes, France on 15 September 2006," Department for Transport 
Available: https://assets.publishing.service.gov.uk/media/5422f68640f0b61342000587/4-2009_G-EZAC.pdf.

Fletcher, S., Norman, P., Galloway, S., and Burt, G., "Solid state circuit breakers enabling optimised protection of DC aircraft power systems," Proceedings of the 2011 14th European Conference on Power Electronics and Applications, 2011, pp. 1-10.

84

Fang Luo, Jian Chen, Xinchun Lin, Yong Kang, and Shanxu Duan, "A novel solid state fault current limiter for DC power distribution network," 2008 Twenty-Third Annual IEEE Applied Power Electronics Conference and Exposition, IEEE, 2008, pp. 1284-1289.

85 Fletcher, S. D. A., Norman, P. J., Fong, K., Galloway, S. J., and Burt, G. M., "High-Speed Differential Protection for Smart DC Distribution Systems," IEEE Transactions on Smart Grid, vol. 5, Sep. 2014, pp. 2610-2617.

86 Michael W. Green, Benjamin T. Schiltgen, and Andrew R. Gibson, "Analysis of a Distributed Hybrid Propulsion System with Conventional Electric Machines," 48th AIAA/ASME/SAE/ASEE Joint Propulsion Conference \& Exhibit, Atlanta, Georgia: AIAA, 2012.

87

Rich Wilby, "The Alverstoke Aviation Society Guide to Aircraft Electrical Systems," Rich and Greg's Airplane Page Available: http://alverstokeaviation.blogspot.co.uk/2016/03/the-alverstoke-aviation-society-guide_25.html. 